\title{
Response of Various Stakeholders towards Newly Introduced Japanese Encephalitis Vaccine in a North Indian State
}

\author{
Dinesh Kumar ${ }^{1}$ and Amar Jeet Singh ${ }^{2}$ \\ ${ }^{1}$ Department of Community Medicine, Dr. Rajendra Prasad Government Medical College, Kangra, Himachal Pradesh 176001, India \\ ${ }^{2}$ Department of Community Medicine, School of Public Health, PGIMER, Chandigarh 160012, India \\ Correspondence should be addressed to Dinesh Kumar; dinesh9809@gmail.com
}

Received 20 August 2014; Revised 14 November 2014; Accepted 14 November 2014; Published 2 December 2014

Academic Editor: Homayon Ghiasi

Copyright (C 2014 D. Kumar and A. J. Singh. This is an open access article distributed under the Creative Commons Attribution License, which permits unrestricted use, distribution, and reproduction in any medium, provided the original work is properly cited.

\begin{abstract}
Introduction. Many attempts had been made to introduce newer vaccines into national immunization schedule of India. Special vaccines campaigns for diseases like JE were also initiated, which required a lot of preparation before vaccinating the beneficiaries. Objectives. To ascertain response of various stakeholders regarding launch of Japanese encephalitis vaccination campaign by state government in district Ambala, Haryana. Methodology. A 30-cluster survey was done to assess the vaccine coverage and views of the stakeholders. Various officials of state health services were also interviewed. Results. JE vaccine coverage was found to be $93.9 \%$. Majority $(59.8 \%)$ of the parents were informed about JE vaccination by the health worker. Many $(83 ; 41.7 \%)$ parents said that they got their child vaccinated for JE since it "endangers life of children" and 82 (41.2\%) said that "since everybody got it." All the staff was trained for JE vaccination campaign. Conclusion. JE vaccination campaign was a success with adequate preparation. Majority of people accepted vaccine in good faith in the government rather than due to their knowledge about disease.
\end{abstract}

\section{Introduction}

Importance of vaccines for communicable disease control was conclusively established with eradication of smallpox in 1980. The Government of India had a national immunization schedule through which children were getting vaccines for tuberculosis, poliomyelitis, diphtheria, tetanus, pertussis, and measles. Some states also included additional vaccines like hepatitis B in the schedule. Many of the newer vaccines were, however, available in private sector, for example, chickenpox, typhoid, hepatitis A, pentavalent vaccine (diphtheria, tuberculosis, tetanus, hepatitis B, and Hemophilus influenza B), and so forth.

The JE vaccine was being used sporadically in India in limited areas since the 1970s. In India, there is a rise of JE incidence and the outbreaks have occurred in 25 states. The majority have been reported from the states of Bihar, Uttar Pradesh, Assam, Manipur, Andhra Pradesh, Karnataka, Madhya Pradesh, Maharashtra, Tamil Nadu, Haryana, Kerala, West Bengal, Orissa, and Union territories of Goa and Pondicherry. JE was reported as an outbreak in the studied state; a serologically confirmed epidemic was reported in the studied area which had affected 182 patients $(88.0 \%$ were children) with mortality rate of $65.0 \%$ [1]. However, largescale special JE vaccination campaign was initiated in 2006 in the states of Assam (coverage 82.76\%), Karnataka (coverage 82.67\%), West Bengal (coverage 56.12\%), and Uttar Pradesh (coverage 99.97\%) and in 2007 in Tamil Nadu and states of Andhra Pradesh, Bihar, and Haryana [2]. In most areas of Asia, the mouse brain vaccine produced from the Nakayama strain is given subcutaneously in 2 doses of $0.5 \mathrm{~mL}(1.0 \mathrm{~mL}$ for people $>3$ years) 1 to 4 weeks apart with a booster dose at 1 year and additional booster doses thereafter at 1- to 3year intervals. It was recommended that the JE vaccination be carried out during interepidemic period in the age group of 1 to 15 years [3].

The present study was planned in Naraingarh block of Ambala district with the objectives to ascertain the knowledge attitude and practices of health care service providers towards Japanese encephalitis vaccination campaign in the study area; ascertain the knowledge attitude and practices of people towards Japanese encephalitis vaccination campaign 
TABLE 1: Age and sex distribution of children selected for coverage evaluation survey of Japanese encephalitis vaccination in Naraingarh, Ambala, Haryana.

\begin{tabular}{lccc}
\hline Age group (years) & Male $N(\%)$ & Female $N(\%)$ & Total $N(\%)$ \\
\hline $1-5$ & $48(58.5)$ & $34(41.5)$ & $82(100)$ \\
$6-10$ & $50(59.5)$ & $34(40.5)$ & $84(100)$ \\
$11-15$ & $21(45.7)$ & $25(54.3)$ & $46(100)$ \\
Total & $\mathbf{1 1 9 ( 5 6 . 1 )}$ & $\mathbf{9 3 ( 4 3 . 9 )}$ & $\mathbf{2 1 2 ( 1 0 0 )}$ \\
\hline
\end{tabular}

in the study area; and determine the JE vaccine coverage in the study area.

\section{Material and Methods}

This study was done in village of Naraingarh block of district Ambala, Haryana, where the state government had recently launched a vaccination drive for Japanese encephalitis. Various stakeholders like accredited social health activists (ASHAs), Anganwadi workers (AWWs), multipurpose health worker-female (MPHWF), medical officers (MOs) from Primary Health Centre (PHC) and Community Health Centre (CHC), and district immunization officer (DIO) were interviewed regarding the degree of their involvement in the JE vaccination campaign. Their views and knowledge about JE vaccine were also assessed.

A 30-cluster vaccine coverage evaluation survey was conducted in the study area. During the survey parents of children were also interviewed regarding their knowledge and views about JE vaccination campaign. Some $(15 ; 7.1 \%)$ school going children of age group 10 to 15 years were interviewed directly instead of their parents, who were not available at home during the survey. The data were entered into SPSS (Statistical Software for Social Sciences) version 15.0 statistical package. Qualitative data were subjected to textual analysis.

\section{Results}

Overall, 212 children were surveyed in 21 villages for immunization coverage and for knowledge of parents about the vaccination (Table 1). Of them 199 (93.9\%) children had been vaccinated for JE during the campaign. Almost half (102, $48.1 \%$ ) of the children belonged to scheduled castes category. Reason for not being vaccinated was reported as "us din voh school nahi gaya tha" (that day, the kid did not go to school). Overall, $178(89.5 \%)$ of the children were immunized in the school. Parents were unaware of immunization dates and other places for immunization.

The majority $(59.8 \%)$ of the parents were informed about JE vaccination by the health worker. Anganwadi helper/school peon (16.1\%), mass media (11.5\%), and neighbor $(4.5 \%)$ were other sources of information. Forty-eight percent of parents were aware that the vaccine will protect against JE, while $46.7 \%$ were not aware about type of disease prevented by the vaccine. Malaria was reported as disease prevented by the rest of $5.5 \%$ cases. Parents of 107 (53.7\%) children considered JE as a serious disease. None of them was aware of signs and symptoms of JE. Eleven (5.5\%) parents reported fever in children after 3-4 days of vaccination, and in four $(2.0 \%)$ cases, swelling was reported at injection site within 2 days following immunization.

Many $(83,41.7 \%)$ parents said that they got their child vaccinated for JE since it "endangers life of children" and 82 (41.2\%) said that "since everybody got it." Almost all (197, 98.9\%) respondents were aware about site of the vaccination. The health worker explained to parents of 42 (21.5\%) children the common side effects.

When respondents were asked about various vaccines available for different diseases, then the majority of respondents told about measles (63.5\%), polio (51.4\%), hepatitis B (49.0\%), whooping cough $(22.2 \%)$, tuberculosis $(14.6 \%)$, tetanus $(11.8 \%)$, diphtheria $(8.5 \%)$, and mumps and rubella (2.4\%).

Fifteen ANMs were interviewed about JE vaccination drive. All of them were aware about guidelines for JEV, for example, age group (1 to 15 years), cold chain management, dose and site, and drugs for management of adverse reactions. All ANMs were aware about the site, dose, cold chain, and contraindications of JE vaccination and $66.6 \%$ were aware about mode of JE transmission. None of them was aware about its case fatality, incubation period, or the cost of vial.

One day prior to training, all ANMs were informed telephonically by the PHC medical officer in charge about their training at $\mathrm{CHC}$. Lectures and video films were used for the training. All of them stated "Is se (JE) bachche ki jaan ko khatra hai, isee liye yeh jarori hai" (it endangers life of children; that is why it is important) as a reason for the importance of JE vaccination. None of them was aware about earlier JE vaccination drives in other districts of state. One ANM said that the vaccination drive helped her professionally, "Is se (JE vaccination drive) logon se meri jan pehchan badhi" (I will get to interact with more people of the area during the drive), "Apne area se bahar kam karne ka bhi mauka mila" (got chance to work beyond our area). Five ANMs stated that "Tike toh ham pehle se lagate hi hai, toh is se (JE vaccination) kya hoga" (we had been providing vaccination earlier also; no additional advantage will be there from this drive). No major adverse reactions were reported by the ANMs during the interview. During the survey two cases of fever with rash were reported 3 days after the vaccination in one village.

Overall, 6 PHC medical officers were interviewed. All felt that JE vaccination was important as it endangered life of children since the disease (JE) had high case fatality rate. One medical officer shared his experience stating that "maine apne dost se suna hai ki ek rajya ke ek gaon me logon ne golian (bullets) tak chala di thi, ki hamare bachche ko pehle davai (JE vaccine) lagao" (I heard from my friend about an incident from a state where people even opened gun fire to insist upon vaccination of their child before the vaccine stock exhausted). All medical officers had received modular training for JE vaccine at district level. All of them stated that vaccination was the only modality of prevention for Japanese encephalitis. They reported to have adequate stock of drugs for management of adverse reactions in their areas. None reported any major adverse reaction due to the vaccine. 
TABLE 2: Evaluation of the preparatory steps taken by the state health services for JE vaccine campaign in Ambala district, Haryana.

\begin{tabular}{|c|c|c|c|}
\hline Areas & Steps/questions & Answers/action taken & Remarks \\
\hline \multirow{5}{*}{ Policy } & $\begin{array}{l}\text { Disease burden and cost-effectiveness } \\
\text { estimations }\end{array}$ & $\begin{array}{l}\text { Annual report Ministry of Health and Family } \\
\text { Welfare, Government of India }\end{array}$ & Done \\
\hline & $\begin{array}{l}\text { Financial sustainability planning for future } \\
\text { years }\end{array}$ & $\begin{array}{l}\text { Targeting introduction into national immunization } \\
\text { schedule }\end{array}$ & Yes \\
\hline & Advocacy and social mobilization & $\begin{array}{l}\text { Participation and training of district level } \\
\text { immunization officer (interview with DIO) }\end{array}$ & Done \\
\hline & Training and material development & Hoardings, pamphlets, banners used & Done \\
\hline & Cold chain capacity assessment & ILRs and vaccine carries used & Done \\
\hline \multirow{4}{*}{$\begin{array}{l}\text { Planning and } \\
\text { operations }\end{array}$} & $\begin{array}{l}\text { Is the implementation in progress according to } \\
\text { the initial plan (countrywide/phased } \\
\text { introduction, key dates)? }\end{array}$ & $\begin{array}{l}\text { Phased introduction in Haryana, and dates }(15 / 7 / 08 \\
\text { to } 31 / 7 / 08 \text { ) were ensured after vaccine stocks (as } \\
\text { interview with DIO) }\end{array}$ & Done \\
\hline & $\begin{array}{l}\text { Is there a transition plan, if the country has or } \\
\text { is planning to switch from one vaccine } \\
\text { presentation to another? }\end{array}$ & $\begin{array}{l}\text { Shifted from mouse brain vaccine to live attenuated } \\
\text { vaccine }\end{array}$ & No \\
\hline & $\begin{array}{l}\text { Are specific adverse events following } \\
\text { immunization (AEFIs) for new vaccine } \\
\text { recognized and reported in timely fashion? }\end{array}$ & $\begin{array}{l}\text { Cases of AEFI following vaccine administration were } \\
\text { discussed and managed }\end{array}$ & Done \\
\hline & $\begin{array}{l}\text { Is surveillance for the new vaccine-related } \\
\text { disease or condition in place? }\end{array}$ & $\begin{array}{l}\text { Integrated Diseases Surveillance Program is in } \\
\text { operation }\end{array}$ & Done \\
\hline \multirow{3}{*}{ Vaccine management } & $\begin{array}{l}\text { Have vaccine stockouts been experienced since } \\
\text { introduction? }\end{array}$ & $\begin{array}{l}\text { Vaccine supply was ensured before implementation } \\
\text { (declaration of dates) }\end{array}$ & Done \\
\hline & $\begin{array}{l}\text { Is there a plan to assess the impact of new } \\
\text { vaccine implementation? }\end{array}$ & $\begin{array}{l}\text { Reduction in JE cases in the region is being } \\
\text { documented }\end{array}$ & Done \\
\hline & $\begin{array}{l}\text { What is the overall perception of introduction } \\
\text { as judged by decision-makers and NIP team? }\end{array}$ & $\begin{array}{l}\text { DIO, MOs, and health workers reported it to be } \\
\text { useful for disease prevention }\end{array}$ & Done \\
\hline $\begin{array}{l}\text { Health worker } \\
\text { practice }\end{array}$ & $\begin{array}{l}\text { Are correct practices observed during } \\
\text { handling, reconstitution, and administering of } \\
\text { vaccines? }\end{array}$ & Observed by the supervisors (medical officers) & Done \\
\hline Immunization safety & $\begin{array}{l}\text { Are autodisable syringes and safety boxes used } \\
\text { and appropriately disposed of? }\end{array}$ & Used & Done \\
\hline Vaccine wastage & $\begin{array}{l}\text { Is vaccine wastage recorded and monitored at } \\
\text { the health facility level? }\end{array}$ & $\begin{array}{l}\text { Recorded by health workers and monitored by } \\
\text { medical officers }\end{array}$ & Done \\
\hline $\begin{array}{l}\text { Health worker } \\
\text { knowledge }\end{array}$ & $\begin{array}{l}\text { Do the health workers need additional training } \\
\text { and supportive supervision on new vaccine? }\end{array}$ & DIO, MOs, and health workers were trained & Done \\
\hline \multirow[t]{2}{*}{$\begin{array}{l}\text { Community } \\
\text { acceptance }\end{array}$} & $\begin{array}{l}\text { Is the new vaccine well received by the } \\
\text { community and the health workers? }\end{array}$ & Coverage was found to be $93.5 \%$ & Done \\
\hline & $\begin{array}{l}\text { Can families name the new vaccine and the } \\
\text { disease it prevents? }\end{array}$ & $48.7 \%$ of parents were able to tell about JE & Satisfactory \\
\hline
\end{tabular}

The district immunization officer (DIO) informed about his participation in national, state, and district level meetings prior to vaccine introduction in his area. He also shared an information that prior to receipt of vaccine supply, an international agency informed that "Aap vaccine dene $k i$ dates declare kar do" (you declare the dates of vaccination campaign); he said that "Hamne (state health services) yeh mana kar diya, kyonki vaccine se pehle dates kaise declare kar den!" (we refused to do so; how can we declare the campaign dates schedule before receiving the vaccine stocks?). He also informed that two cases of syncope were reported after the vaccine administration. They were managed successfully.

\section{Discussion}

JE vaccine was used in Haryana in the present campaign. The present study demonstrated a high level (93.9\%) of JE vaccine coverage in the study area. In contrast, another study from a neighboring urban area in 2004 reported a coverage among 0 - to 5 -year children for new vaccines like hepatitis B (44.7\%), Hemophilus influenza (27.8\%), mumps, measles, rubella (27.6\%), and typhoid (2.8\%) [4]. The higher coverage for JE vaccine in the present instance was due to vigorous campaign by the state health services. About $75 \%$ parents were aware about the schedule, but only $48.7 \%$ of parents were aware that it prevents JE. Another study from Delhi tested 
knowledge among general population and found that less were aware about the immunization day (37.0\%), about age of vaccination $(49.1 \%)$, and about three vaccine preventable diseases (39.3\%) [5]. Apparently, in the present study area, it was the faith of community in government vaccination drive which helped the high coverage of the JE vaccine.

Acceptance of the vaccine by the community is not entirely dependent on their correct knowledge and awareness about the etiology/prevention of the diseases, but also on mass media campaigns. All that mattered to the public was that the government was providing the vaccine free of cost. It was observed that a community accepts vaccine program in good faith without even understanding the basics like disease type, individual vulnerability, modes of prevention, and so forth. Instead of knowledge, it is faith in the government that worked. Consumers and brand loyal people tend to stick to a tested and reliable product. Their faith in the brand affects their purchasing behavior. Brand equity is the value inherent in a well-known brand name, and in the JE vaccine campaign the brand was the government [6].

It had been said that social and professional attitude to a vaccine or a vaccine program may "make or break" the program. Adjaye, however, found that parental attitude towards immunization was greatly influenced by medical and nonmedical health professions [6], while Berkeley in a study of attitude towards measles vaccine found that the professionals themselves were unsure about the contraindications to vaccine and its value [7]. Campbell, in analyzing the reasons for poor uptake of the measles vaccine in Britain, suggested that attitude and ignorance, a cumbersome policy making bureaucracy, and the absence of legislation were some of the reasons for unpopularity of measles vaccine in Britain [8].

Thus, in contrast to India, the lower literacy situation did not prevent the high coverage rate for JE vaccine in this specific campaign, possibly because of public faith in a government sponsored vaccine. Introduction of a newer vaccine in an immunization schedule of any country in the modern era with adequate preparation of health care delivery system for organization and administration of vaccine needs to be done. In this study, almost all the preparatory steps were ensured before introduction of the new vaccination campaign (Table 2).

\section{Conclusion}

Requisite preparatory steps were taken at all levels before introduction of JE vaccine in Ambala district of Haryana. However, the acceptance of JE vaccine by the community was more due to people's faith in government services followed by their awareness about the disease or vaccine. This may be because of the lower literacy level of parents. However, people may, in the future, care more for the finer aspects of vaccines like efficiency, safety, scientific basis of program, and so forth, when literacy level improves in the community.

\section{Conflict of Interests}

The authors declare that there is no conflict of interests regarding the publication of this paper.

\section{References}

[1] S. R. Prasad, V. Kumar, R. K. Marwaha, K. L. Batra, R. K. Rath and S. R. Pal, "An epidemic of encephalitis in Haryana: serological evidence of Japanese encephalitis in a few patients," Indian Pediatrics, vol. 30, no. 7, pp. 905-910, 1993.

[2] G. P. S. Dhillon and V. K. Raina, "Epidemiology of Japanese encephalitis in context with Indian scenario," Journal of the Indian Medical Association, vol. 106, no. 10, pp. 660-663, 2008.

[3] Japanese Encephalitis in India, History and Recent Developments, PATH, 2004.

[4] A. Kumar, N. Holla, K. Lalitha, and S. Pruthvish, "Operational knowledge about routine immunization amongst medical officers," in Proceedings of the 52nd National Conference of Indian Public Health Association, 2008.

[5] L. G. Schiffman and L. L. Kanuk, Consumer Behaviour, Pearson Education, New Delhi, India, 8th edition, 2004.

[6] N. Adjaye, "Measles immunization. Some factors affecting nonacceptance of vaccine," Public Health, vol. 95, no. 4, pp. 185-188, 1981.

[7] M. I. Berkeley, "Measles-the effect of attitudes on immunisation," Heath Bulletin, vol. 41, no. 3, pp. 141-147, 1983.

[8] A. G. M. Campbell, "Measles immunisation: why have we failed?" Archives of Disease in Childhood, vol. 58, no. 1, pp. 35, 1983.

[9] "Expanded program on immunization," in Proceedings of the 31st Session of WHO Regional Committee, Report and Working Papers, World Health Organization, 1978. 

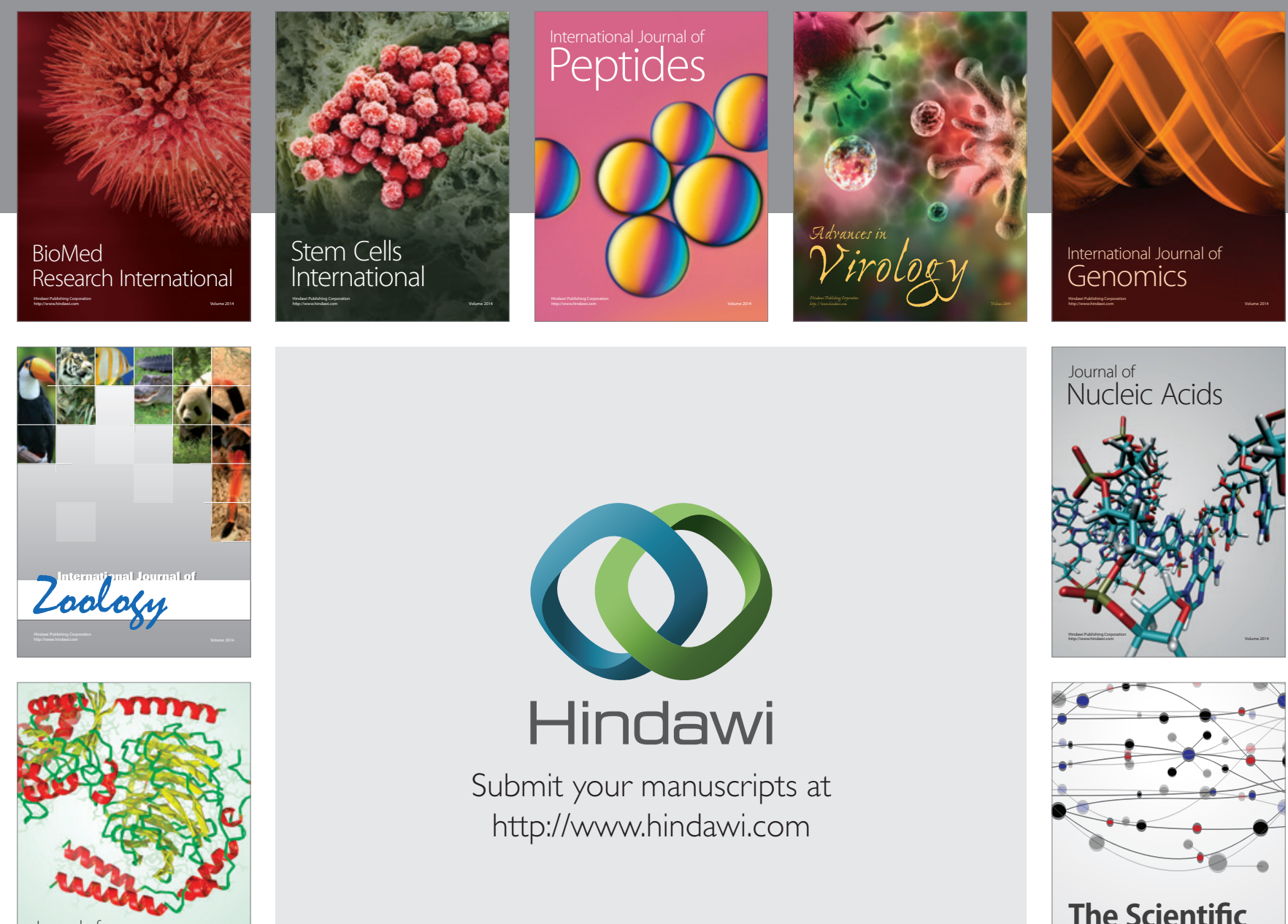

Submit your manuscripts at

http://www.hindawi.com

Journal of
Signal Transduction
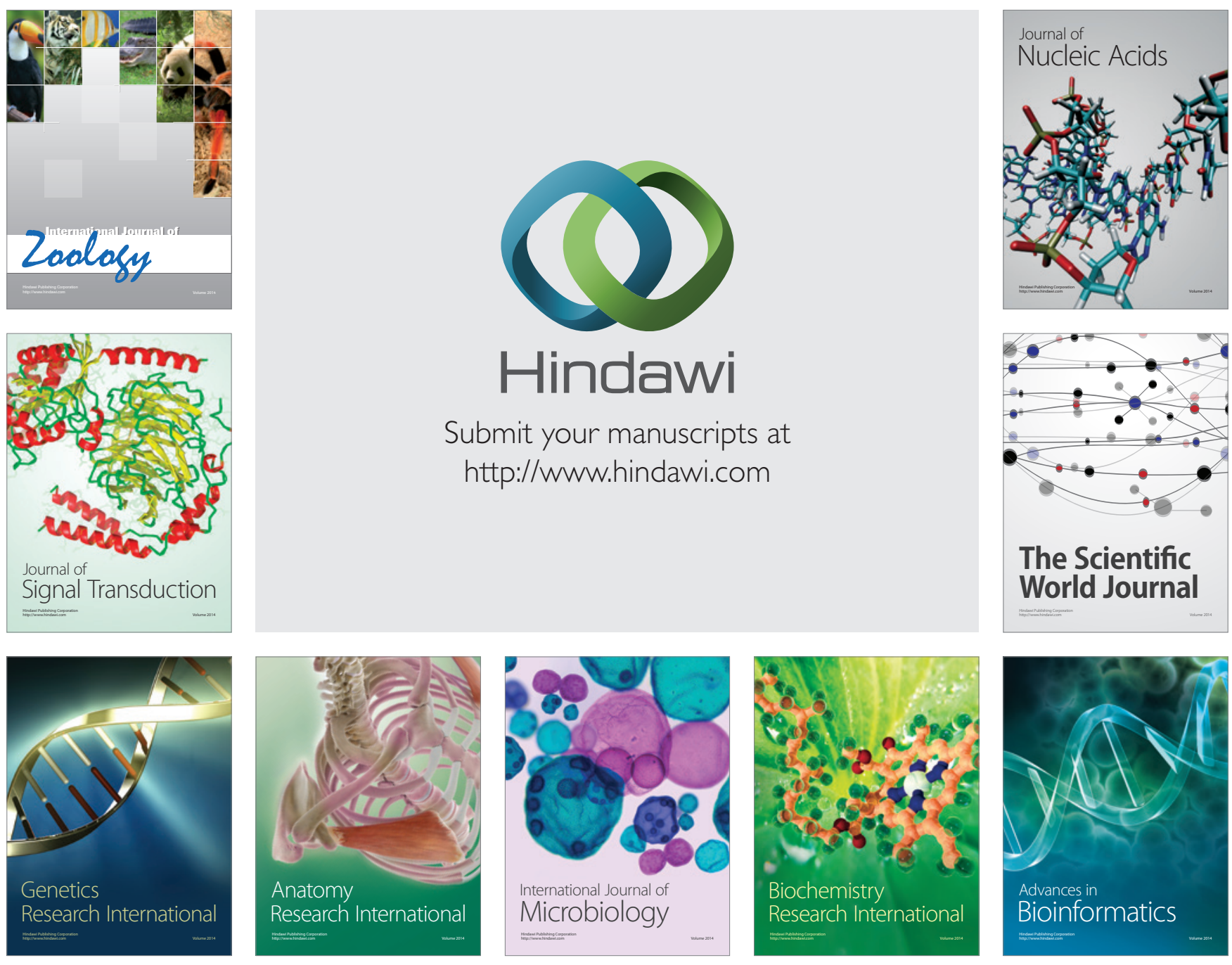

The Scientific World Journal
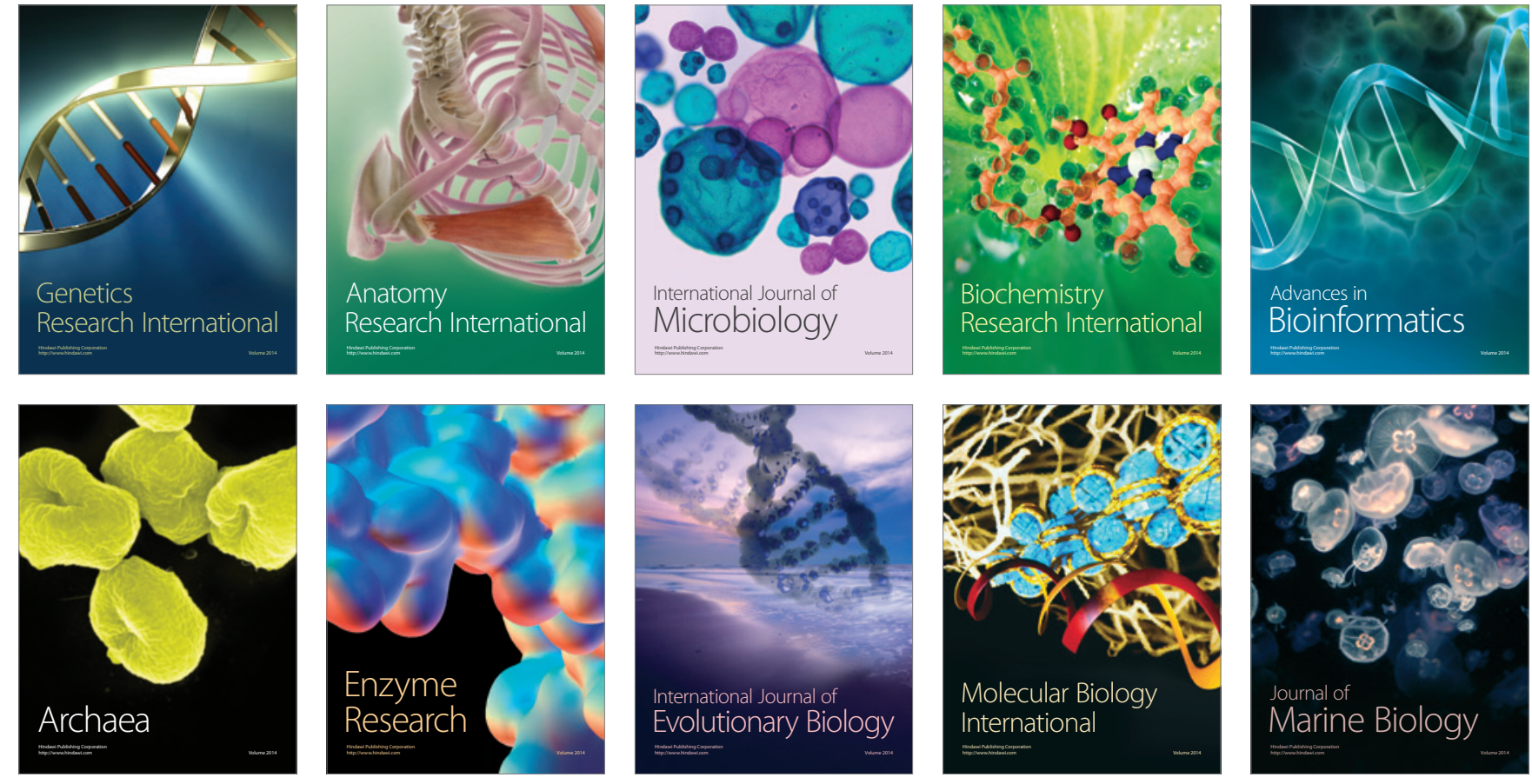